\title{
Hyperprolactinemia during antipsychotics treatment increases the level of coagulation markers
}

\author{
This article was published in the following Dove Press journal: \\ Neuropsychiatric Disease and Treatment \\ 24 February 2015 \\ Number of times this article has been viewed
}

\section{Masamichi Ishioka \\ Norio Yasui-Furukori \\ Norio Sugawara \\ Hanako Furukori \\ Shuhei Kudo \\ Kazuhiko Nakamura}

Department of Neuropsychiatry, Graduate School of Medicine, Hirosaki University, Hirosaki, Japan

Correspondence: Norio Yasui-Furukori Department of Neuropsychiatry, Graduate School of Medicine, Hirosaki University, Hirosaki 036-8562, Japan

Tel +8I I72395066

Fax +8I I72395067

Email yasufuru@cc.hirosaki-u.ac.jp
Objective: The strong association between psychiatric patients who receive antipsychotics and the incidence of venous thromboembolism (VTE) is known. Although previous reports suggest that hyperprolactinemia often increases markers of activated coagulation, few studies have examined the direct relationship between the prolactin level elevated by antipsychotics and activated markers of activated coagulation.

Method: The participants included 182 patients with schizophrenia ( male $=89$, female $=93$ ) who received antipsychotic treatments for at least 3 months. Markers of VTE (D-dimer, fibrin/ fibrinogen degradation products, and thrombin-antithrombin complex) and serum prolactin concentrations were measured.

Results: Prolactin levels were significantly correlated with the logarithmic transformation of the D-dimer $(r=0.320, P=0.002)$ and fibrin/fibrinogen degradation product levels ( $r=0.236, P=0.026)$ but not of the thrombin-antithrombin complex level ( $r=0.117, \mathrm{~ns})$ among men. However, no correlations were found between the VTE markers and prolactin levels among women. These results were confirmed using multiple regression analyses that included demographic factors and antipsychotic dosages.

Conclusion: The current study indicates that hyperprolactinemia is associated with an increase in markers of activated coagulation among men receiving antipsychotics. This finding clinically implies that monitoring and modulating prolactin levels among men are important to decrease the risk of VTE.

Keywords: prolactin, antipsychotics, venous thromboembolism

\section{Introduction}

Venous thromboembolism (VTE) affects one to two in 1,000 adults, causing severe mortality and morbidity. ${ }^{1}$ VTE comprises deep venous thromboembolism and pulmonary embolism. The risk factors for VTE include advanced age, obesity, hypertension, diabetes, dyslipidemia, pregnancy, major surgery, and hormone replacement therapy. ${ }^{1-3}$ In addition, particular psychiatric patients under physical restraints, with catatonia, or with neuroleptic malignant syndrome are at high risk of VTE. ${ }^{4-6}$ In addition, antipsychotic drug use is known as a risk factor of VTE. There have been several VTE case reports in psychiatric patients receiving antipsychotics between the 1950s and 1980s. ${ }^{7}$ This relationship was also discovered among patients receiving clozapine in the $1990 \mathrm{~s} .{ }^{8}$ However, the association between the use of antipsychotics and VTE remains unclear. Almost all studies have suggested a positive relationship between antipsychotic use and VTE, and these studies have estimated a wide range of risk from 1.1 to $29.3,{ }^{9-18}$ with only one study indicating negative findings. ${ }^{17}$

Because the prolactin response to antipsychotics is related to dopamine D2-receptor blockade, ${ }^{19-21}$ hyperprolactinemia is a frequent consequence of certain antipsychotic 
treatments. Prolactin responses to antipsychotics are greater among women than among men. The major effects of hyperprolactinemia among women include amenorrhea, galactorrhea, the cessation of normal cyclic ovarian function, loss of libido, occasional hirsutis, ${ }^{22,23}$ and long-term osteoporosis risk. ${ }^{24}$ The effects among men include impotence, loss of libido, hypospermatogenesis, ${ }^{22,23}$ and the long-term risk of low bone density. ${ }^{24}$

Several studies have suggested that increased levels of prolactin are associated with platelet aggregation. ${ }^{25,26}$ Erem et $\mathrm{al}^{27}$ reported that the levels of fibrinogen and antithrombin III among patients with prolactinoma were significantly increased compared with control participants. Similarly, Anaforoglu et $\mathrm{al}^{28}$ found that adenosine diphosphate (ADP)-stimulated expression was significantly greater in the hyperprolactinemia group than in the control group; this ADP-stimulated expression provides evidence of platelet activation. Based on these findings, prolactin is regarded as a hormone-associated coagulant, and patients with hyperprolactinemia are considered at risk for VTE. The sedative effect of antipsychotics might cause VTE.

Recently, Skokou and Gourzis ${ }^{29}$ reported a case of pulmonary embolism in a woman with bipolar disorder who was treated with amisulpride, aripiprazole, and paroxetine. Although the contribution of aripiprazole and paroxetine cannot be excluded completely, the most likely factor underlying the thromboembolic event was hyperprolactinemia (92 $\mathrm{ng} / \mathrm{mL}$ ) caused by the amisulpride.

We hypothesized that hyperprolactinemia during antipsychotic treatment is associated with VTE among psychiatric patients. Therefore, we examined the effect of elevated prolactin levels on enhanced coagulation in psychiatric patients treated with antipsychotics. In addition, sex-specific effects were evaluated because prolactin responses to antipsychotics differ between men and women.

\section{Methods}

\section{Participants}

This study was conducted at Hirosaki-Aiseikai Hospital (Hirosaki, Japan), Kuroishi-Akebono Hospital (Kuroishi, Japan), and Hirosaki University Hospital (Hirosaki, Japan). The sample consisted of patients registered between January 1, 2012 and September 1, 2013. All patients (58 inpatients and 124 outpatients) had schizophrenia and were aged between 18 and 90 years. We conducted the present study after obtaining approval from the Ethics Committee at the Hirosaki University School of Medicine. Participants provided written informed consent after receiving a full description of the study. To be included in this study, the participants could not have received hormone replacement therapy or any anticoagulant or oral contraceptive medications.

Patients who were pregnant, had malignant tumors, had a history of requiring physical restraint over the last 3 months, or had difficulty walking were excluded. The patients must have received the same antipsychotic treatment for more than 3 consecutive months. Research psychiatrists conducted the psychiatric diagnoses using the Structured Clinical Interview for the Diagnostic and Statistical Manual of Mental Disorders, Fourth Edition, of the American Psychiatric Association. Participants were coded as having schizophrenia, mood disorders, or dementia and were classified as either positive or negative for hypertension, diabetes, or dyslipidemia. Their current smoking status was also recorded.

\section{Procedure}

Blood samples were drawn between 7 am and 10 am. We did not control when the meal and medication were taken prior to sampling blood. A cubital vein blood sample was taken and divided into two aliquots after the anthropometric assessments.

Body weight and body mass index (BMI) (weight in $\mathrm{kg}$ / height squared) were assessed. The blood levels of D-dimer, fibrinogen degradation products (FDP), and thrombinantithrombin complex (TAT) were also assessed.

\section{Chemical analyses}

Determining serum prolactin and markers of activated coagulation

Blood samples were drawn into vacuum tubes containing sodium citrate and ethylenediaminetetraacetic acid as anticoagulants. The blood samples were separated into plasma and cells using centrifugation. Plasma samples were stored at $-20^{\circ} \mathrm{C}$ for later use. Serum prolactin concentrations were measured using an automated electrochemiluminescence immunoassay (Roche Diagnostics, Tokyo, Japan). The coefficients of variation (CVs) of the intra- and interassays were less than $10 \%$. Normal CV ranges are $4.3-13.7 \mu \mathrm{g} / \mathrm{L}$ for men, 4.9-29.3 $\mu \mathrm{g} / \mathrm{L}$ for women prior to menopause, and 3.1-15.4 $\mu \mathrm{g} / \mathrm{L}$ for women after menopause. D-dimer and FDP measurements were performed by the latex flocculation method using commercial kits for D-dimer (Kainos Laboratories, Inc., Tokyo, Japan) and FDP (Sekisui Medical Co., Ltd, Tokyo, Japan). Normal ranges are $<1.0 \mu \mathrm{g} / \mathrm{L}$ for D-dimer and $<5 \mu \mathrm{g} / \mathrm{mL}$ for FDP. A TAT assay was performed with an enzyme-linked immunosorbent assay (TFB, Inc., Tokyo, Japan). The normal range is $<3 \mathrm{ng} / \mathrm{mL}$. 


\section{Statistical analyses}

We compared descriptive statistics (age, height, body weight, BMI, duration of illness, and chlorpromazine equivalent) between men and women using Student's $t$-test. Unless otherwise stated, continuous variables are expressed as the mean \pm standard deviation (SD). Logarithmic conversions were performed for nonnormally distributed variables, including D-dimer (log D-dimer), FDP ( $\log$ FDP), and TAT ( $\log$ TAT). For multiple statistical comparisons between the three activated coagulation factors, we applied Bonferroni's corrections.

To investigate the relationship between prolactin levels and individual markers of activated coagulation, correlations among these variables were determined using Pearson's correlation analysis. Moreover, the individual markers of activated coagulation were calculated in the controls for different levels of prolactin $(\mu \mathrm{g} / \mathrm{L})$. We compared levels across the 0th-25th (first quantile), 25th-50th (second quantile), 50th-75th (third quantile), and 75th-100th (fourth quantile) percentiles. Each group was examined via a one-way analysis of variance. Multiple regression analysis was performed to determine the correlations between the markers of activated coagulation (log D-dimer, $\log$ FDP, and $\log$ TAT) and the clinical variables for each group and for all participants. In the between-group analyses, the markers of activated coagulation were set as the dependent variables, and age, sex, BMI, hypertension, diabetes, dyslipidemia, smoking status, chlorpromazine equivalent, and prolactin level were set as the independent variables.

The data were skewed. Statistical analyses were performed using SPSS 21.0 (IBM Corporation, Armonk, NY).

\section{Results}

Table 1 summarizes the clinical characteristics and laboratory parameters for all participants, divided by sex. The median age and corresponding SD were 53.0 \pm 13.4 years for the men and $47.0 \pm 16.5$ years for the women. This difference was significant $(P=0.008)$. The median \pm SD prolactin level was $25.6 \pm 21.1 \mu \mathrm{g} / \mathrm{L}$ for men and $52.7 \pm 57.5 \mu \mathrm{g} / \mathrm{L}$ for women; this difference was significant $(P<0.001$; Table 1$)$. Men were significantly older than women $(P=0.008)$. The body weight for men was significantly higher than that for women ( $P=0.024$, Table 1). However, the BMI of women was significantly higher than that of men $(P=0.020$; Table 1$)$. The dose of antipsychotic administered to men was higher than that administered to women $(P=0.048$; Table 1$)$.

Among all the participants, prolactin levels were not significantly correlated with the markers of activated coagulation (Table 2). However, a positive correlation was observed between prolactin and markers of activated coagulation such as $\log \mathrm{D}$-dimer $(P=0.002)$ and $\log \operatorname{FDP}(P=0.026)$ among the men. However, after applying Bonferroni's correction,

Table I Demographic of patients receiving antipsychotics treatment

\begin{tabular}{|c|c|c|c|}
\hline & Men $(n=89)$ & Women $(n=93)$ & Significance \\
\hline Age (years) & $53.0 \pm 13.4$ & $47.0 \pm 16.5$ & $P=0.008$ \\
\hline Age range (years) & $28-79$ & $18-84$ & \\
\hline Duration of illness (months) & $24.8 \pm 14.3$ & $17.1 \pm 11.3$ & $P<0.001$ \\
\hline Height (cm) & $168.0 \pm 7.3$ & $156.5 \pm 5.5$ & $P<0.00$ I \\
\hline Body weight (kg) & $67.0 \pm 14.3$ & $62.2 \pm 13.7$ & $P=0.024$ \\
\hline Body mass index $\left(\mathrm{kg} / \mathrm{m}^{2}\right)$ & $23.7 \pm 4.5$ & $25.4 \pm 5.3$ & $P=0.020$ \\
\hline Current smoker & $43 \%$ & $20 \%$ & \\
\hline \multicolumn{4}{|l|}{ Comorbidity } \\
\hline Hypertension & $n=16(18.0 \%)$ & $\mathrm{n}=13(\mid 4.0 \%)$ & \\
\hline Diabetes & $\mathrm{n}=\mathrm{I} \mid(\mid 2.3 \%)$ & $\mathrm{n}=\mathrm{II}(\mathrm{II} .8 \%)$ & \\
\hline Dyslipidemia & $n=16(18.0 \%)$ & $\mathrm{n}=23(24.7 \%)$ & \\
\hline \multicolumn{4}{|c|}{ Number of different antipsychotic drugs received } \\
\hline 1 & $45(50.6 \%)$ & $57(61.3 \%)$ & \\
\hline 2 & $26(29.2 \%)$ & $30(32.3 \%)$ & \\
\hline$\geq 3$ & $18(20.2 \%)$ & $6(6.5 \%)$ & \\
\hline Chlorpromazine equivalent (mg/day) & $678.1 \pm 479.6$ & $548.6 \pm 394.0$ & $P=0.048$ \\
\hline Prolactin $(\mu g / L)$ & $25.6 \pm 21.1$ & $52.7 \pm 57.5$ & $P<0.001$ \\
\hline D-dimer $(\mu g / L)$ & $0.5 \pm 0.8$ & $0.5 \pm 0.9$ & $P=0.577$ \\
\hline $\operatorname{FDP}(\mu g / L)$ & $3.6 \pm 3.8$ & $3.2 \pm 2.8$ & $P=0.535$ \\
\hline TAT (mg/L) & $9.0 \pm 26.4$ & $4.1 \pm 4.2$ & $P=0.090$ \\
\hline
\end{tabular}

Note: Data show mean \pm standard deviation.

Abbreviations: FDP, fibrin/fibrinogen degradation products; TAT, thrombin-antithrombin complex. 
Table 2 Correlation between prolactin and coagulation factors

\begin{tabular}{|c|c|c|c|c|c|c|}
\hline & \multicolumn{2}{|c|}{ All participants $(\mathrm{N}=192)$} & \multicolumn{2}{|c|}{ Men $(\mathbf{N}=89)$} & \multicolumn{2}{|c|}{ Women $(\mathrm{N}=93)$} \\
\hline & $\boldsymbol{r}$ & Significance & $\boldsymbol{r}$ & Significance & $\boldsymbol{r}$ & Significance \\
\hline Log D-dimer & 0.105 & $P=0.158$ & 0.320 & $P=0.002$ & 0.018 & $P=0.866$ \\
\hline Log FDP & 0.071 & $P=0.339$ & 0.236 & $P=0.026$ & 0.020 & $P=0.849$ \\
\hline Log TAT & 0.002 & $P=0.974$ & 0.117 & $P=0.276$ & 0.026 & $P=0.806$ \\
\hline
\end{tabular}

Note: For D-dimer, FDP, and TAT, logarithmic conversions were performed because of nonnormally distributed variables.

Abbreviations: FDP, fibrin/fibrinogen degradation products; TAT, thrombin-antithrombin complex.

the significance of the correlation between prolactin and FDP disappeared. Conversely, no correlation was observed between the prolactin level and markers of activated coagulation among the women (Figure 1). Table 3 shows the means of the markers of activated coagulation in the four prolactin groups. These results indicate a significant difference in the D-dimer level among men $(P=0.048$; Figure 1$)$ but not among women.

Table 4 shows the multiple regression results for the markers of activated coagulation. Among men, age, hypertension, diabetes, and prolactin level were significantly associated with $\log \mathrm{D}$-dimer. Furthermore, only age and BMI were positively associated with log FDP among men. Log TAT was not associated with any of the dependent variables among men and women. Only age was positively associated with $\log$ D-dimer among women. Age and hypertension were significantly associated with $\log$ FDP. The dose of antipsychotics was not associated with any marker of activated coagulation in men or women.

Only half of the patients were receiving antipsychotic monotherapy. Among them, no correlations were observed between the prolactin levels and the markers of activated coagulation in any subgroup of patients receiving a given antipsychotic medication.

\section{Discussion}

The results of this study indicated that the prolactin level was significantly correlated with certain markers of activated coagulation (log D-dimer and log FDP) in men receiving antipsychotic treatments. This study is the first to show an association between the prolactin level and VTE risk among psychiatric patients. Our data showed that men with higher levels of prolactin had enhanced markers of activated coagulation (log D-dimer and $\log$ FDP) but that women did not show this tendency.

Raaz et $\mathrm{al}^{21}$ suggested that a high density of prolactin enhances the ADP-stimulated aggregation of platelets. However, prolactin alone does not influence the process of aggregation; rather, the combination of prolactin and adrenalin does. Prolactin and adrenalin do not lead to platelet aggregation separately. Prolactin affects aggregation through the Gq protein, which induces the shape change of activated platelets. Prolactin receptors are not directly related to Gq proteins; rather, they bypass G-protein-related pathways and directly interact with protein kinase C. Protein kinase C, coupled to protein $\mathrm{Gq}$, is a key enzyme in the signal transduction pathway.

Several case control studies have suggested that the risk of VTE gradually rises with increasing levels of prolactin. These studies have found an association between prolactin levels and VTE, ${ }^{19,30}$ although the evidence for the link between prolactin and the occurrence of VTE in psychiatric patients remains inconclusive. However, almost all of these studies included fewer than 30 patients with hyperprolactinemia. Therefore, the strength of the current study is its large sample size of approximately 100 men and women with hyperprolactinemia, which is nearly three times that of any previous study..$^{27,28}$

No significant differences in any marker of activated coagulation were observed between men and women in this study. This result may be explained by the opposing effects of age and BMI on each sex. In this study, the age of the men was significantly higher than that of the women $(P=0.008)$. Alternatively, the BMI of the women was significantly higher than that of the men $(P=0.020)$. As a result, the effects of aging and high BMI, which are known to be risk factors for VTE, on the markers of activated coagulation might have offset each other in men and women. In addition, although the daily dose of antipsychotics administered to men was significantly higher than that administered to women ( $P=0.048)$, no difference in the ratio of chlorpromazine equivalent $(\mathrm{mg} /$ day) to body weight $(\mathrm{kg})$ was detected between men and women $(P=0.500)$. Therefore, it is assumed that the blood concentration of this antipsychotic may not be different between men and women.

Twenty-three of the 192 patients received aripiprazole in this study. Several previous studies have shown that aripiprazole exerts a negligible effect on prolactin concentration ${ }^{31}$ 

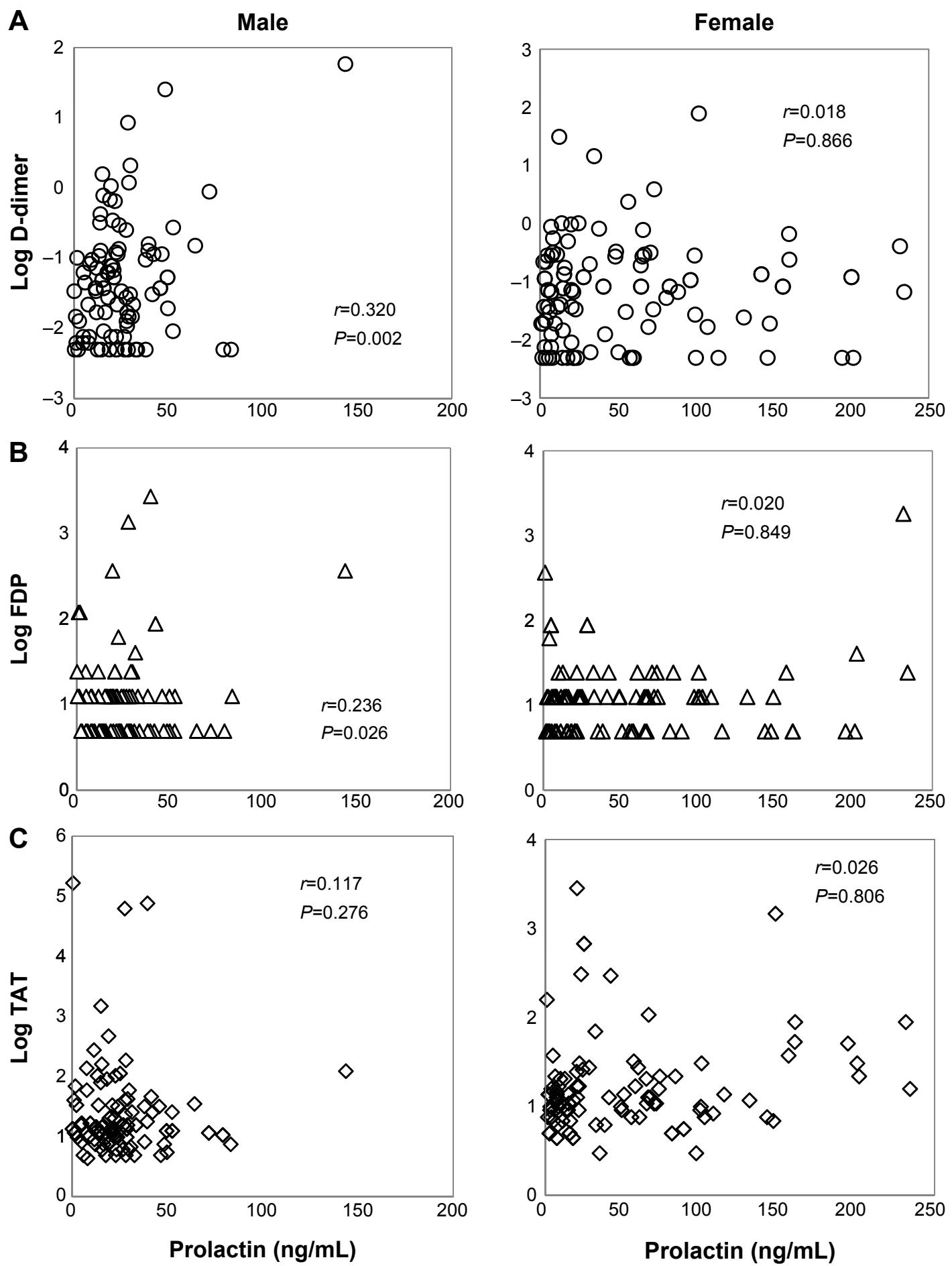

Figure I Scatter diagram of coagulation factor and prolactin in male and female patients.

Notes: Relationship between prolactin and log D-dimer (A), relationship between prolactin and log FDP (B), relationship between prolactin and log TAT (C).

Abbreviations: FDP, fibrin/fibrinogen degradation products; TAT, thrombin-antithrombin complex.

and alleviates the increases in the prolactin concentrations induced by other antipsychotics ${ }^{32}$ but that other antipsychotics often increase the prolactin concentrations. ${ }^{33}$ Therefore, this mixed patient cohort might not display any association between the markers of activated coagulation and the dose of antipsychotic.
The prolactin levels of women were nearly twice those of men in this study. Nevertheless, prolactin was correlated with the markers of activated coagulation levels only in men. We hypothesize that differences in illness duration might have influenced this result. The median $\pm \mathrm{SD}$ illness duration among men was $24.8 \pm 14.3$ years, whereas that among 
Table 3 Coagulation factor associated with different percentiles of prolactin

\begin{tabular}{|c|c|c|c|c|c|c|c|}
\hline Percentile & Prolactin $(\mu g / L)$ & D-dimer $(\mu g / L)$ & & FDP $(\mu \mathrm{g} / \mathrm{mL})$ & & TAT (ng/mL) & \\
\hline \multicolumn{8}{|l|}{ All participants $(\mathrm{N}=192)$} \\
\hline First quantile $(n=56)$ & $0.14-9.46$ & $0.36 \pm 0.34$ & & $2.64 \pm 0.78$ & & $7.07 \pm 24.56$ & \\
\hline Second quantile $(n=57)$ & $9.54-21.7$ & $0.45 \pm 0.6 \mathrm{I}$ & & $3.47 \pm 3.15$ & & $6.31 \pm|5.9|$ & \\
\hline Third quantile $(n=57)$ & $22.2-49.5$ & $0.54 \pm 0.78$ & $F=2.57$ & $3.65 \pm 4.16$ & $F=1.70$ & $5.99 \pm 17.12$ & $F=0.24$ \\
\hline Fourth quantile $(n=57)$ & $49.7-343.9$ & $0.78 \pm I .31$ & $P=0.055$ & $3.98 \pm 3.88$ & $P=0.17$ & $4.4 I \pm 3.7 I$ & $P=0.87$ \\
\hline \multicolumn{8}{|l|}{ Men $(\mathrm{N}=89)$} \\
\hline First quantile $(n=28)$ & $0.14-12.0$ & $0.32 \pm 0.39$ & & $2.43 \pm 0.57$ & & $9.59 \pm 34.40$ & \\
\hline Second quantile $(n=27)$ & $|2|-2 \mid .0$. & $0.40 \pm 0.30$ & & $3.8 \mathrm{I} \pm 4.08$ & & $8.26 \pm 22.71$ & \\
\hline Third quantile $(n=27)$ & $21.1-32.6$ & $0.4 I \pm 0.53$ & $F=2.72$ & $3.00 \pm 1.59$ & $F=2.270$ & $4 . I I \pm 2.3 I$ & $F=0.34$ \\
\hline Forth quantile $(n=27)$ & $33.5-143.6$ & $0.80 \pm 1.36$ & $P=0.048$ & $4.89 \pm 6.00$ & $P=0.085$ & $10.00 \pm 4.78$ & $P=0.80$ \\
\hline \multicolumn{8}{|l|}{ Women $(\mathrm{N}=93)$} \\
\hline First quantile $(n=29)$ & $0.37-8.4$ & $0.34 \pm 0.25$ & & $2.76 \pm 0.87$ & & $4.55 \pm 5.52$ & \\
\hline Second quantile $(n=30)$ & $8.9-23.8$ & $0.5 \mathrm{I} \pm 0.8 \mathrm{I}$ & & $3.17 \pm 2.02$ & & $4.0 I \pm 4.25$ & \\
\hline Third quantile $(n=30)$ & $24.7-72.8$ & $0.67 \pm 0.93$ & $F=1.09$ & $3.50 \pm 2.32$ & $F=1.082$ & $3.56 \pm 2.25$ & $F=0.31$ \\
\hline Fourth quantile $(n=29)$ & $73.4-343.9$ & $0.74 \pm 1.35$ & $P=0.36$ & $4.03 \pm 4.62$ & $P=0.360$ & $4.03 \pm 2.83$ & $P=0.82$ \\
\hline
\end{tabular}

Note: Data show range for prolactin and mean \pm standard deviation for D-dimer, FDP, and TAT.

Abbreviations: FDP, fibrin/fibrinogen degradation products; TAT, thrombin-antithrombin complex.

women was $17.1 \pm 11.3$ years, representing a significant difference ( $P=0.001$; Table 1$)$. The recorded illness duration was similar to the length of the patients' antipsychotic treatments. Therefore, men might be exposed to higher levels of prolactin over a longer period.

The mechanisms that underlie the sex differences in VTE remain unknown. At the molecular level, sex differences affect platelets and markers of activated coagulation activity, and sex hormones such as estrogen regulate markers of activated coagulation. ${ }^{30,34,35}$ For example, hyperprolactinemia results in low levels of estrogen, and this hormone is associated with coagulation activity. ${ }^{35,36}$ Therefore, certain markers of activated coagulation might offset the elevated prolactin concentrations in women. ${ }^{37,38}$ However, because we did not measure the levels of sex hormones, whether sex hormones affected our results remains unknown.

The levels of D-dimer and FDP (but not TAT) were positively associated with prolactin levels in men. In general,

Table 4 Variables identified by multiple regression analysis as predicting coagulation factor in male and female patients

\begin{tabular}{|c|c|c|c|c|c|c|c|}
\hline \multirow[t]{2}{*}{ Sex } & \multirow[t]{2}{*}{ Predictor } & \multicolumn{2}{|c|}{ Log D-dimer } & \multicolumn{2}{|c|}{ Log FDP } & \multicolumn{2}{|c|}{ Log TAT } \\
\hline & & $\beta$ & Significance & $\beta$ & Significance & $\beta$ & Significance \\
\hline \multirow[t]{9}{*}{ Men } & Prolactin & 0.221 & $P=0.030$ & 0.132 & $P=0.218$ & 0.098 & $P=0.394$ \\
\hline & Age & 0.379 & $P=0.030$ & 0.336 & $P=0.006$ & 0.065 & $P=0.612$ \\
\hline & BMI & 0.259 & $P=0.021$ & 0.249 & $P=0.036$ & 0.085 & $P=0.502$ \\
\hline & Chlorpromazine equivalent & -1.749 & $P=0.084$ & -0.029 & $P=0.786$ & 0.109 & $P=0.344$ \\
\hline & Hypertension & -0.217 & $P=0.038$ & -0.147 & $P=0.182$ & -0.061 & $P=0.608$ \\
\hline & Diabetes & -0.210 & $P=0.035$ & -0.176 & $P=0.094$ & 0.109 & $P=0.335$ \\
\hline & Dyslipidemia & 0.073 & $P=0.467$ & -1.042 & $P=0.300$ & -0.095 & $P=0.4 \mid 4$ \\
\hline & Current smoker & 0.025 & $P=0.804$ & -0.041 & $P=0.709$ & -0.019 & $P=0.872$ \\
\hline & $R$ & 0.537 & $P<0.001$ & 0.443 & $P=0.020$ & 0.240 & $P=0.764$ \\
\hline \multirow[t]{9}{*}{ Women } & Prolactin & 0.021 & $P=0.816$ & 0.009 & $P=0.919$ & 0.020 & $P=0.857$ \\
\hline & Age & 0.438 & $P<0.001$ & 0.479 & $P<0.00$ I & -0.500 & $P=0.665$ \\
\hline & BMI & 0.172 & $P=0.074$ & 0.082 & $P=0.372$ & 0.111 & $P=0.327$ \\
\hline & Chlorpromazine equivalent & 0.039 & $P=0.687$ & 0.006 & $P=0.949$ & 0.001 & $P=0.991$ \\
\hline & Hypertension & 0.108 & $P=0.269$ & 0.245 & $P=0.011$ & 0.085 & $P=0.469$ \\
\hline & Diabetes & 0.124 & $P=0.206$ & 0.039 & $P=0.678$ & 0.090 & $P=0.448$ \\
\hline & Dyslipidemia & -0.080 & $P=0.423$ & -0.089 & $P=0.353$ & -0.065 & $P=0.587$ \\
\hline & Current smoker & 0.175 & $P=0.07 I$ & 0.026 & $P=0.775$ & 0.066 & $P=0.568$ \\
\hline & $R$ & $0.58 \mathrm{I}$ & $P<0.001$ & 0.620 & $P<0.001$ & 0.190 & $P=0.921$ \\
\hline
\end{tabular}

Note: For D-dimer, FDP, and TAT, logarithmic conversions were performed because of nonnormally distributed variables. Abbreviations: BMI, body mass index; FDP, fibrin/fibrinogen degradation products; TAT, thrombin-antithrombin complex. 
obtaining a blood sample from a small and dehydrated vein can falsely elevate plasma TAT levels. Omote et al ${ }^{39}$ indicated that several plasma markers of activated coagulation, including D-dimer and TAT, changed under various difficult sampling conditions, with the exception of D-dimer. Difficult sampling methods did not influence plasma D-dimer levels. Therefore, we hypothesize that the plasma TAT levels of this study might have been increased by difficult sampling, and that the relationship between plasma TAT and prolactin levels might not be significant.

Several factors are indisputably involved in VTE. The reasonable hypothesis concerning the formation of VTE must be judged in the context of three basic factors: damage to the vessel wall, venous stasis, and the abnormal process of coagulation. ${ }^{40}$ These three factors are known as Virchow's triad. However, we did not evaluate all factors involved in VTE. Additional studies are required to clarify the mechanisms responsible for VTE in psychiatric patients.

Because damage to the vessel wall is primarily associated with operations or bone fractures, this mechanism has little influence on the patient group that received antipsychotics. We assumed that the mechanisms of both the abnormal process of coagulation and venous stasis influenced the markers of activated coagulation in the patient group. Antipsychotics, which are often used in combination with psychotropic medications, might cause sedation and reduce daily activity, thereby contributing to venous stasis. The lifestyles of patients on long-term antipsychotics are characterized by a lack of exercise, weight gain, and unhealthy diets. Furthermore, metabolic symptoms caused by antipsychotics, such as weight gain, hyperglycemia, and dyslipidemia, increase the risk for VTE. ${ }^{41,42}$

Because many articles have reported that aging increases the risk for VTE, ${ }^{43}$ the influence of age might be stronger than the level of prolactin on the markers of activated coagulation in this study. In fact, the effect sizes (partial correlation coefficients) of age were greater than those of prolactin in both men ( 0.379 vs 0.221 for $\log \mathrm{D}$-dimer and 0.336 vs 0.132 for $\log$ FDP) and women ( 0.438 vs 0.021 for $\log$ D-dimer and 0.479 vs 0.009 for log FDP) (Table 4). The stratification of patients according to age is required for examining the influence of prolactin on the risk of VTE.

The present study had several limitations. First, we did not employ a control group; thus, we were unable to compare our results or determine the relationship between VTE and the level of prolactin in healthy individuals. Second, we studied patients with several psychiatric diseases; thus, the direct influence that each disease has on the markers of activated coagulation remains unknown. Furthermore, measuring the influence that illness severity has on markers of activated coagulation is difficult because we did not evaluate the diseases using that scale. Third, we measured several markers of activated coagulation but did not investigate VTE itself using a multislice computed tomography scanner. Therefore, whether increases in these markers of activated coagulation cause VTE is unknown and should be investigated in the future. Fourth, although many risk factors for VTE were examined as potential confounders in the current study, other risk factors such as family history and thrombophilia were not recorded. This lack of data might underestimate the risk of VTE, but because thrombophilia is rare, our findings are unlikely to change substantially.

\section{Conclusion}

Hyperprolactinemia is associated with an increase in markers of activated coagulation among men receiving antipsychotics. Additional studies are required to prospectively evaluate the relationship between the level of prolactin and VTE among patients receiving antipsychotics.

\section{Acknowledgments}

This study was funded by a Grant-in-Aid for Scientific Research (KAKENHI) from the Japan Society for the Promotion of Science (JSPS, 20333734), the Mitsubishi Pharma Research Foundation, and the Asteras Schizophrenia Research Foundation and a grant from the Hirosaki Research Institute for Neuroscience.

\section{Disclosure}

Norio Yasui-Furukori has received grant/research support or honoraria from, and spoken for, Astra, Dainippon, Eli Lilly, GSK, Janssen-Pharma, Meiji, Mochida, MSD, Otsuka, Pfizer, Takada, and Yoshitomi. The remaining authors declare that they have no competing interests. The funders had no role in the study design, data collection/analysis, the decision to publish, or preparation of the manuscript.

\section{References}

1. Kyrle PA, Eichinger S. Deep vein thrombosis. Lancet. 2005;365: 1163-1174.

2. Ageno W, Squizzato A, Garcia D, Imberti D. Epidemiology and risk factor of venous thromboembolism. Semin Thromb Hemost. 2006;32(7): 651-658.

3. Anderson FA Jr, Spencer FA. Risk factors for venous thromboembolism. Circulation. 2003;107(23 Suppl 1):9-16.

4. Laursen SB, Jensen TN, Bolwig T, Olsen NV. Deep venous throbosis and pulmonary embolism following physical restraint. Acta Psychiatr Scand. 2005;111(4):324-327. 
5. Lachner C, Sandson NB. Medical complications of catatonia: a case of catatonia-induced deep venous thrombosis. Psychosomatics. 2003; 44(6):512-514.

6. Addonizio G, Susman VL, Roth SD. Neuroleptic malignant syndrome: review and analysis of 115 cases. Biol Psychiatry. 1987;22(8): 1004-1020.

7. Hägg S, Spigset O. Antipsychotic-induced venous thromboembolism: a review of the evidence. CNS Drugs. 2002;16(11):765-776.

8. Zornberg GL, Jick H. Antipsychotic drug use and risk of first-time idiopathic venous thromboembolism: a case-control study. Lancet. 2000;356(9237):1219-1223.

9. Parkin L, Skegg DC, Herbison GP, Paul C. Psychotropic drugs and fatal pulmonary embolism. Pharmacoepidemiol Drug Saf. 2003;12(8): 647-652.

10. Lacut K, Le Gal G, Couturaud F, et al. Association between antipsychotic drugs, antidepressant drugs and venous thromboembolism: results from the EDITH case-control study. Fundam Clin Pharmacol. 2007;21(6):643-650.

11. Ray JG, Mamdani MM, Yeo EL. Antipsychotic and antidepressant drug use in the elderly and the risk of venous thromboembolism. Thromb Haemost. 2002;88(2):205-209.

12. Jönsson AK, Horváth-Puhó E, Hägg S, Pedersen L, Sørensen HT. Antipsychotics and risk of venous thromboembolism: a populationbased case-control study. Clin Epidemiol. 2009;1:19-26.

13. Hamanaka S, Kamijo Y, Nagai T, et al. Massive pulmonary thromboembolism demonstrated at necropsy in Japanese psychiatric patients treated with neuroleptics including atypical antipsychotics. Circ J. 2004; 68(9):850-852.

14. Liperoti R, Pedone C, Lapane KL, et al. Venous thromboembolism among elderly patients treated with atypical and conventional antipsychotic agents. Arch Intern Med. 2005;165(22):2677-2682.

15. Thomassen R, Vandenbroucke JP, Rosendaal FR. Antipsychotic medication and venous thrombosis. Br J Psychiatry. 2001;179:63-66.

16. Kleijer BC, Heerdink ER, Egberts TC, et al. Antipsychotic drug use and the risk of venous thromboembolism in elderly patients. $J$ Clin Psychopharmacol. 2010;30(5):526-530.

17. Chris P, Carol C, Julia H. Antipsychotic drugs and risk of venous thromboembolism: nested case-contorol study. BMJ. 2010;341:c4245.

18. Shulman M, Jennifer N, Manu N. Thrombotic complications of treatment with antipsychotics drugs. Minerva Med. 2013;104:175-184.

19. Heida NM, Schäfer K, Konstantinides S. Prolactin as a modulator of platelet function and thrombosis: the end of the story, or a new beginning? Thromb Haemost. 2009;101(6):991-992.

20. Horrobin DF, McNeilly AS, Jackson FS, et al. Letter: prolactin and myocardial infarction. Lancet. 1973;2(7840):1261.

21. Raaz D, Wallaschofski H, Stumpf C, et al. Increased prolactin in acute coronary syndromes as putative Co-activator of ADP-stimulated P-selectin expression. Horm Metab Res. 2006;38(11):767-772.

22. Byerly M, Suppes T, Tran QV, et al. Clinical implications of antipsychotic-induced hyperprolactinemia in patients with schizophrenia spectrum or bipolar spectrum disorders: recent developments and current perspectives. J Clin Psychopharmacol. 2007;27(6):639-661.

23. Bostwick JR, Guthrie SK, Ellingrod VL. Antipsychotic-induced hyperprolactinemia. Pharmacotherapy. 2009;29(1):64-73
24. Meaney AM, Smith S, Howes OD, et al. Effects of long-term prolactinraising antipsychotic medication on bone mineral density in patients with schizophrenia. Br J Psychiatry. 2004;184:503-508.

25. Yavuz D, Deyneli O, Akpinar I, et al. Endothelial function, insulin sensitivity and inflammatory markers in hyperprolactinemic pre-menopausal women. Eur J Endocrinol. 2003;149(3):187-193.

26. Urban A, Masopust J, Malý R, et al. Prolactin as a factor for increased platelet aggregation. Neuro Endocrinol Lett. 2007;28(4):518-523.

27. Erem C, Kocak M, Nuhoglu I, et al. Blood coagulation, fibrinolysis and lipid profile in patients with prolactinoma. Clin Endocrinol (Oxf). 2010;73(4):502-507.

28. Anaforoglu I, Ertorer ME, Kozanoglu I, et al. Macroprolactinemia, like hyperprolactinemia, may promote platelet activation. Endocrine. 2010; 37(2):294-300

29. Skokou M, Gourzis P. Pulmonary embolism related to amisulpride treatment: a case report. Case Rep Psychiatry. 2013;718950.

30. Kurrelmeyer K, Becker L, Becker D, et al. Platelet hyperreactivity in women from families with premature atherosclerosis. J Am Med Womens Assoc. 2003;58(4):272-277.

31. Leucht S, Cipriani A, Spineli L, et al. Comparative efficacy and tolerability of 15 antipsychotic drugs in schizophrenia: a multipletreatments meta-analysis. Lancet. 2013;382(9896):951-962.

32. Yasui-Furukori N, Furukori H, Sugawara N et al. Dose-dependent effects of adjunctive treatment with aripiprazole on hyperprolactinemia induced by risperidone in female patients with schizophrenia. J Clin Psychopharmacol. 2010;30(5):596-599.

33. Peuskens J, Pani L, Detraux J, et al. The effects of novel and newly approved antipsychotics on serum prolactin levels: a comprehensive review. CNS Drugs. 2014;28(5):421-453.

34. Faraday N, Goldschmidt-Clermont PJ, Bray PF. Gender differences in platelet GPIIb-IIIa activation. Thromb Haemost. 1997;77(4): 748-754.

35. Becker DM, Segal J, Vaidya D, et al. Sex differences in platelet reactivity and response to low-dose aspirin therapy. JAMA. 2006;295(12): 1420-1427.

36. Kluft C, Lansink M. Effect of oral contraceptives on haemostasis variables. Thromb Haemost. 1997;78(1):315-326.

37. Majumdar A, Mangal NS. Hyperprolactinemia. J Hum Reprod Sci. 2013;6(3):168-175.

38. Woodward M, Lowe GD, Rumley A, et al. Epidemiology of coagulation factors, inhibitors and activation markers: the Third Glasgow MONICA Survey. II. Relationships to cardiovascular risk factors and prevalent cardiovascular disease. Br J Haematol. 1997;97(4):785-797.

39. Omote M, Asakura H, Takamichi S, et al. Changes in molecular markers of hemostatic and fibrinolytic activation under various sampling conditions using vacuum tube samples from healthy volunteers. Thromb Res. 2008;123(2):390-395.

40. Lowe GD. Virchow's triad revisited: abnormal flow. Pathophysiol Haemost Thromb. 2003;33(5-6):455-457.

41. Liperoti R, Gambassi G. Antipsychotics and the risk of venous thromboembolism. BMJ. 2010;341:c4216.

42. Dunn EJ, Grant PJ. Type 2 diabetes: an atherothrombotic syndrome. Curr Mol Med. 2005;5(3):323-332.

43. Beckman MG, Hooper C, Critchley SE, et al. Venous thromboembolism: a public health concern. Am J Prev Med. 2010;38(4 Suppl): S495-S501.

Neuropsychiatric Disease and Treatment

\section{Publish your work in this journal}

Neuropsychiatric Disease and Treatment is an international, peerreviewed journal of clinical therapeutics and pharmacology focusing on concise rapid reporting of clinical or pre-clinical studies on a range of neuropsychiatric and neurological disorders. This journal is indexed on PubMed Central, the 'PsycINFO' database and CAS, Association (INA). The manuscript management system is completely online and includes a very quick and fair peer-review system, which is all easy to use. Visit http://www.dovepress.com/testimonials.php to read real quotes from published authors. 